\title{
Analysis of Development Characteristics and Formation Mechanism of Geo-hazards in Youyu County,Shanxi Province
}

\author{
DING Feng ${ }^{1 a *}$ WANG Dongdong ${ }^{2 b}$ CEN Shihong ${ }^{3 \mathrm{c}}$ \\ ${ }^{1}$ School of Management China university of Mining \& Technology (Beijing), PRC. \\ ${ }^{2}$ College of earth science and engineering Shandong University of Science \& Technology, PRC. \\ ${ }^{3}$ Zhengzhou University of Industrial Technology, PRC.

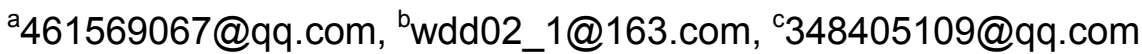

Key words: geo-hazards; countermeasures; Youyu County

Abstract-According to onsite investigation and analysis of the geo-hazards in Youyu County, their main types are identified as landslide, collapse, debris flow and surface collapse. The causes are analyzed in terms of topography, lithology, rainfall and other factors. The research result has shown that the geo-hazards of Youyu County is closely related to rainfall and human engineering activities. The paper suggests that standardized management of the engineering activities and flood season monitor are critical to the geo-hazards counter measures in Youyu County.

\section{Introduction}

In order to ascertain mechanism of inducing geo-hazards, it is the basis of prevention and control of geo-hazards. The paper discussed in detail investigation and analysis of the geo-hazards in Youyu County, determined mainly geological hazard type and mechanism of inducing geo-hazards. Finally, the paper suggests counter measures in Youyu County.

\section{Basic summary of Youyu County}

The territory of Youyu County surrounded by mountains, between hilly, craggy, are Youyu mountain basin. The altitude of eastern Youyu County is between 1,500 and 1,900 m. Its main peak of Hongjia mountain is $1,969.3 \mathrm{~m}$ above sea level, which is the highest mount.

The altitude of west of Youyu county, main peak of Leigong mountain is $1,914 \mathrm{~m} \mathrm{high}$. The altitude of south of Youyu County, main peak of Gaojia mountain is 1,552 $\mathrm{m}$ high. The altitude of basin is 1,250 and $1480 \mathrm{~m}$ high. Shahukou valley 1,230 meters above sea level is the lowest-based habitat. The main controlling structures are the NE-trending faults. The main rocks are sandstone, mudstone and loess.

Youyu County belongs to the North Temperate Zone continental monsoon climate, which is very dry and windy. The rainy season continues from May to October every year.

The rainfall averages $403.6 \mathrm{~mm}$ in a year. It provides advantage for geo-hazard.

\section{Inducing characteristics of geo-hazards}

\section{Type of geo-hazards}

According to the investigation, there are 3 types of geo-hazard in Youyu County. 
There are 30 hazards in Youyu County, including 5 surface collapse, 24 unstable slope and 1 debris flow.

Physiographically, most of them formatted in mountainous slope zone, which sloped angle is more than $25^{\circ}$. They were controlled by terrain obviously, and they were characterized by valleys developing at both banks of the river. From the time, debris flow and unstable slope frequently occurred in rainy season.

With the economic development in Youyu County, the influence of human engineering activity to the geological environment strengthened constantly. The main inducing factors of geo-hazards are as follows: rainfall, earthquake, ecological degradation, bourg construction, agricultural activities, repairing roads, construction of water conservancy project.

\section{Scale of geo-hazards}

Accord to body by volume, geo-hazards can be classified into four categories-huge, large, medium and small in Youyu County.

Geo-hazards mainly are small size. Among which there are 2 large scale hazards, 7 medium scale hazards and 21 small scale hazards in Youyu County.

Table 1 Statistical table of scale of geological hazards in Youyu County

\begin{tabular}{|c|c|c|c|}
\hline Grade & Unstable Landslide $/ \mathbf{1 0}^{\mathbf{4}} \mathbf{m}^{\mathbf{3}}$ & Collapse $/ \mathbf{1 0}^{\mathbf{4}} \mathbf{m}^{\mathbf{3}}$ & Debris-flow $/ \mathbf{1 0}^{\mathbf{4}} \mathbf{m}^{\mathbf{3}}$ \\
\hline Large & - & 2 & - \\
\hline Medium & 6 & 1 & - \\
\hline Small & 18 & 2 & 1 \\
\hline
\end{tabular}

\section{Distribution features of geo-hazards}

Because of the influence of topography, geological and climate conditions, geotectonic movement and human engineering activity, there are obvious differences in distribution features of geo-hazards in Youyu County. Geo-hazards in Youyu mainly distributed in Dingjiayao town, Youwei town, Yangqianhe town, Yuanbaozi town, Weiyuan town, Lidayao town.

\section{Topography distribution of geo-hazards}

Geo-hazards in Youyu County mainly distributed in hilly area. There is poor continuity in mount body, which intercept is very high. Top of mountain is round and valley is very shallow. The depth of cut is about $100 \mathrm{~m}$. The slope of mount is from $15^{\circ}$ to $30^{\circ}$. Vegetative cover develops more.

Because of great population and continual human engineering activity, it resulted in degradation of the natural vegetation. Once it rains heavily, it will lead to happen landslide or debris-flow.

\section{Lithology distribution of geo-hazards}

Clastic rock, carbonatite, metamorphic rock and magmatic rock are widely distributed in Youyu County. According to the investigation, geo-hazard points in Youyu County main distribute in clastic rock area carbonatite and metamorphic rock.

\section{Analysis of forming conditions and inducing factors}

\section{Formation conditions}

\section{Conditions of landform and geomorphy}

Steep extent is landform important condition for formation of geo-hazard. And it is also basic forming condition on landslip, collapse and debris-flow. According to the investigation, geo-hazards spatial pattern had a close relationship with terrain parameters. The geo-hazards distribute widely in Youyu County, including unstable slope, debris-flow 
and collapse of mined-out area in coal mines. The main reason is mountain about the relative elevation of about 300-600 meters. The $\mathrm{U}$ and $\mathrm{V}$-shaped valleys are regularly seen here. Loose slope sediments in hill are easy to form landslide.

\section{Conditions about stratum-lithology}

Rock and soil are material conditions for formation of geo-hazards and they restrict the occurrence and development of geo-hazards. The development degree of geo-hazards depends on type of rock and soil, lithology, structure and engineering geo-characteristics. Geo-hazards in Youyu County mainly distributed in clastic rock. The upper part of stratum-lithology is eluvium with pebbly clay. While the upper part of stratum-lithology is strongly weathered siltstone and shale, which thickness is $2-7 \mathrm{~m}$, the structure of overburden strata and soil is loose and it has big porosity. Under fully hydrous conditions, the interface of strata and soil is easy to form landslide.

\section{The conditions of geological structure}

Large-area Pliocene epoch-Miocene epoch Youyu-basalt formatted during Himalayan Movement. Youyu-basalt exposed as wide as 600 square kilometers. When joint and fracture of rock is well developed, it made rock weathered strongly and its shear strength is significantly reduction, which resulted in formation and development of geo-hazards. At the same time, joint and fracture of rock is easy to weather. Groundwater is infiltrate into joint and fracture of rock. Soft structural plane frequently develop into slip surface. So the belt of joint and fracture is prime location for geo-hazards.

\section{Inducing factors of geo-hazards}

\section{Rainfall influence}

Rainfall is the major effect factors for inducing landslide and debris-flow. When rain sinks into soil, the shearing strength of rock and soil become low. The number of geo-hazards is proportionate to the increased volume of rainfall.

\section{Human influence}

Though the investigation, natural factors caused 25 points and human engineer activity caused 5 points. Consequently, it is shown that in all the geo-hazards caused by human engineer activity mainly for collapse caused by mining. What's more, especially in rural areas, cutting slope to build house, and lead to lowering the slope stability.

\section{Conclusion}

The forming and development of geo-hazards is controlled by various factors, which interior factors include stratum, lithology, landform, geomorphy and geological structure, while external factors include human engineer activity-mining. Rainfall is an important inducement factor. All factors led to the form and development of geo-hazards. Landslide and collapse are determined by intrinsic factors.

The factors that influence the occurrence of geo-hazards are natural, geological environment and human engineering activity factors.

The monitoring of geo-hazards is a key task for disaster prevention. 


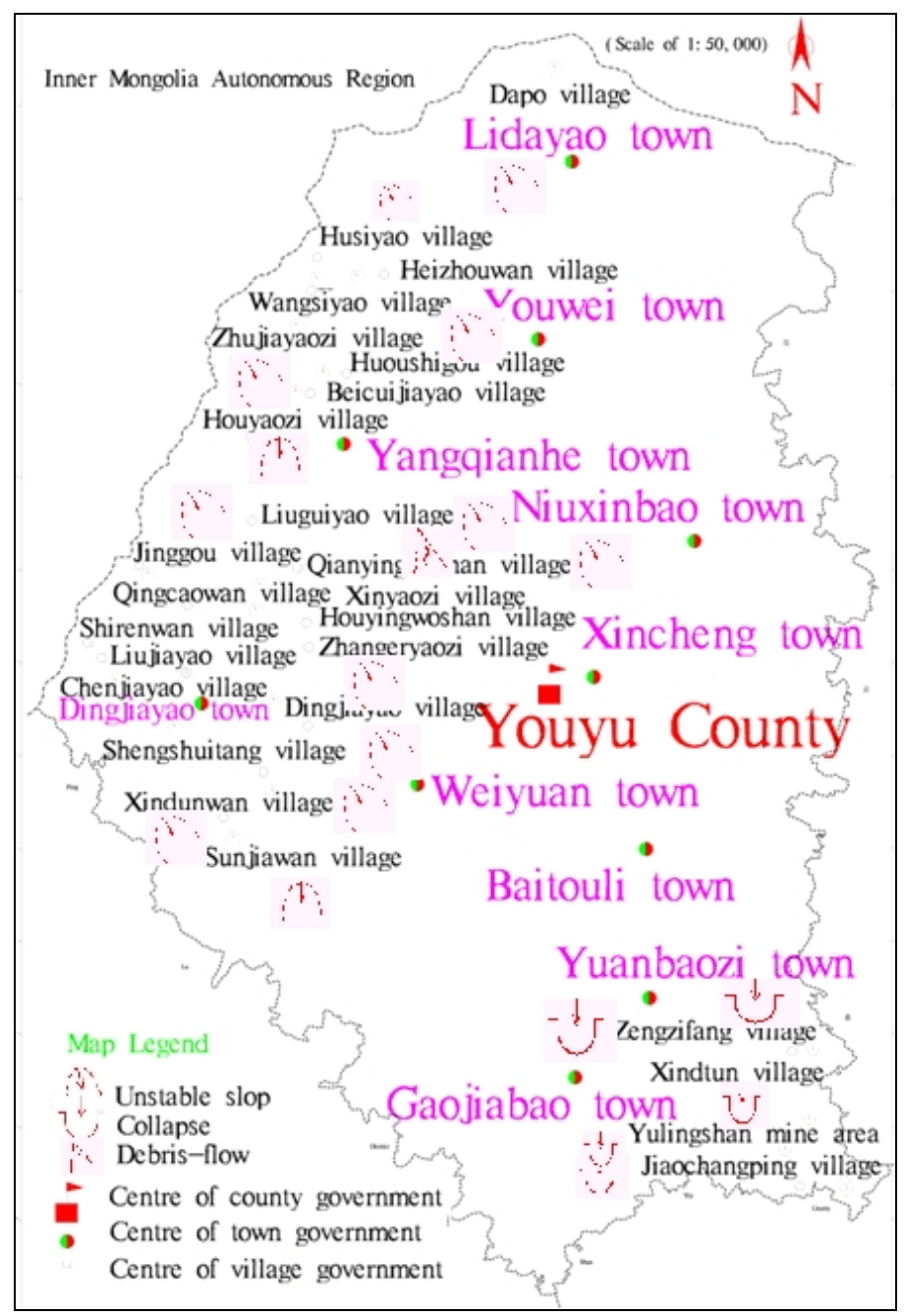

Fig1 Distribution map of geo-hazards in Youyu County

\section{REFERENCES}

[1]YIN Yueping, The preliminary study on geological damage strategic in China[J].The Chinese Journal of geo-hazard and Control 2004,15(2):2-3

[2]DING Feng; Wang Dongdong; Shao Longyi; Wang Lijie, Risk assessment on collapse in Pinglu district of Shuozhou City,Shanxi Province 2012 World Automation Congress, WAC 2012, Puerto Vallarta,Mexico.

[3]Ministry of Land and Resources of the People's Republic of China

《Investigating the geo-hazard and zoning basic requirements about County (City) of the implementation rules 》 2007.

[4]DING Feng. Geological Hazards Mechanism and Risk Assessment in Pinglu District \& Shuocheng District. PhD Dissertation. Beijing, China University of Mining\&technology, 2012. (In Chinese) 